\title{
Qualquer coisa de intermédio: imagens de escrita no filme Conversa Acabada (João Botelho, 1981)
}

\section{Bruno Fontes \\ Estudos Avançados em Materialidades da Literatura - Faculdade de Letras da Universidade de Coimbra}

Resumo: Conversa Acabada (João Botelho, 1981) é um filme que, evidenciando uma conceção da imagem cinematográfica como "plana" e uma noção de reconhecimento, investigação e exploração do seu próprio dispositivo, se serve da representação fílmica das obras de Fernando Pessoa e de Mário de Sá-Carneiro para fornecer uma evidência que o cinema de carácter mais hegemónico tende a ocultar: a heterogeneidade material do meio cinematográfico. Através de conceitos teóricos propostos por André Bazin e por Ágnes Pethő, o propósito deste artigo será demonstrar que o filme, servindo-se de um tipo de imagem afim à de uma superfície através de recursos como a intermedialidade e a reflexividade, apresenta diferentes formas de inscrever a escrita no filme.

Palavras-chave: Conversa Acabada, João Botelho, Escrita e cinema, Intermedialidade, Reflexividade

\begin{abstract}
Conversa Acabada (João Botelho, 1981) is a film that with its conception of the cinematic image as «flat» and a notion of recognition and examination of its own apparatus, uses the filmic depiction of the works of Fernando Pessoa and Mário de Sá-Carneiro to provide an evidence that cinema of a more hegemonic character tends to conceal: the material heterogeneity of the cinematic medium. Through theoretical concepts proposed by André Bazin and Ágnes Pethő, the purpose of this article is to establish that this film, by means of a type of image similar to that of a surface and through resources such as intermediality and reflexivity, presents various forms to inscribe writing on the film.
\end{abstract}

Keywords: Conversa Acabada, João Botelho, Writing and cinema, Intermediality, Reflexivity 
"Um filme [Conversa Acabada], como uma banda desenhada, sem profundidade, à superfície, como se os actores fossem marionetas portadoras de texto", afirma João Botelho (apud Veiga 2010) acerca do seu filme sobre Fernando Pessoa e Mário de Sá-Carneiro. Esta alusão à banda desenhada é menos "excêntrica" do que pode parecer, pois Botelho afirma que desenhou um storyboard para os seus três primeiros filmes, entre os quais Conversa Acabada.

O storyboard, que muito latamente é uma sequência de ilustrações criadas com o objetivo de pré-visualizar um filme, tem como principal finalidade marcar as passagens da história que será contada de uma forma próxima da do aspeto final de projeção. Poder-se-á, assim, ter uma perceção visual das nuances da sequencialidade e da interligação das cenas. A semelhança entre a banda desenhada e o cinema é motivada pelo facto de aquela forma pictórica e narrativa também contar uma história através de uma sequência de quadros, utilizando recursos como a espacialidade, a composição do plano, o enquadramento e a combinação luz/sombra. Portanto, o storyboard pode ser entendido, ao mesmo tempo, como um desenvolvimento do guião do filme na forma de um esboço, tanto mais que "[u]m guião, ao contrário de um esboço, é um carácter num esquema notacional e numa linguagem [...]. Apesar de a maior parte dos guiões serem verbais, a notacionalidade não depende obviamente do aspecto das marcas" (Goodman apud Veiga 2010).

Botelho emprega também, na sua afirmação, o termo "superfície", denotando uma consciência da imagem cinematográfica como plana e aproximando-a da pintura e da fotografia, sendo por este motivo percecionada em simultâneo, tal como estas duas vertentes artísticas, como bidimensional e como tridimensional. E este destaque da superfície e de uma relação com a banda desenhada é claramente demonstrativo, acima de tudo, de uma conceção de um cinema subordinado a uma lógica do enquadramento, ou seja, concebido enquanto forma como se filma e como se coloca a câmara - portanto, de um cinema de reconhecimento, investigação e exploração do seu próprio dispositivo.

Mas Conversa Acabada é acima de tudo, como Botelho declara com a expressão "marionetas portadoras de texto", um filme de textos, onde comparecem excertos da correspondência epistolar entre os dois poetas e uma seleção de textos literários, totais ou 
parciais, tanto da autoria de Pessoa $^{1}$ como de Sá-Carneiro. ${ }^{2}$ Trata-se, portanto, de um filme que se serve dos mesmos como pretexto para a edificação da sua estrutura, sendo significativa a frequência e a importância dada às cenas e aos planos em que estas personagens ${ }^{3}$ encaram não a objetiva, mas o papel em que escrevem, ou ao detalhe das suas caligrafias enquanto compõem os referidos textos, bem como a outros tipos de focalização en abyme da escrita.

Uma presença tão evidente de texto escrito na imagem fílmica e de momentos que retratam a criação literária per se fornece a evidência que o cinema de carácter mais hegemónico tende a ocultar: a heterogeneidade material do meio cinematográfico. Com efeito, e mesmo num vasto número de "filmes de escritores", verificamos antes uma constante ocultação, ou mesmo elisão, dos vestígios de qualquer escrita, sendo esta substituída por recursos fílmicos como a voz over. ${ }^{4}$ Não é o que acontece neste filme, onde as dinâmicas tanto de geração como de fixação da imagem se baseiam numa realidade textual, e em que as relações entre escrita e cinema são aquilo que revela - ou torna dominante - a superfície material desse meio, que se afirma através de momentos de inscrição de ideias de literatura no filme.

Esta situação não é, naturalmente, uma novidade nos meios da imagem, e vários antecedentes seus poderiam ser mencionados. Um deles, bastante revelador, pode ser encontrado no estudo El Arte de Describir: El Arte Holandés en el Siglo XVII, de Svetlana Alpers, no qual a autora, no capítulo intitulado "Palabras para la Vista", alude à constância com que este período artístico apresenta cenas de escrita e de leitura, que se transformaram num motivo pictórico onde uma superfície - a pintura - servia como dispositivo mnemónico para aludir a um texto significativo através da confluência de dois materiais de expressão distintos. Um dos exemplos mais curiosos que a autora convoca é um díptico de Gabriel Metsu, Cavalheiro escrevendo uma carta/Dama lendo uma carta, que reconhece abertamente o caráter representativo da carta não apenas por situá-la entre outras superfícies capazes de representação (desde logo, a pintura que a retrata), mas, mais especificamente, porque a sublinha como medium de comunicação, já que os correspondentes "dependen de la carta para su representación. Separados por sus marcos, 
en sus estancias separadas, estos amantes pueden estarse hasta el fin de los tempos pendientes de la representación del amor, sin participar nunca del amor mismo" (Alpers 1987: 274).

O exemplo apontado por Alpers é também útil para compreender Conversa Acabada. Com efeito, e particularmente durante os momentos de escrita, a câmara está quase sempre fixa, captando as personagens em planos médios de ângulo frontal que tendem a ser longos. A montagem durante as cenas é reduzida ao mínimo, fornecendo o efeito geral de uma sucessão de diferentes tableaux. Assim, oscilando entre o movimento e a estase, o filme apela a algo que constitui a essência e a ontologia do cinema: o seu carácter fotográfico. Epstein, pioneiro do cinema, tanto na teoria quanto na prática, foi dos primeiros a salientarem a transmutação do descontínuo no contínuo realizado pelo cinematógrafo, ou, mais precisamente, a sua capacidade para sintetizar elementos imóveis e descontínuos num todo homogéneo que inaugura um novo conceito de perceção para pensar o tempo, como refere Guido (2012: 144). O próprio storyboard de Botelho já enuncia essa distinção primordial entre movimento e estase, bem como a intenção de privilegiar a imagem parada e o plano fixo enquanto recursos para criar um tipo de imagem que, sendo afim à de uma superfície de inscrição, admita, em todo o caso, diferentes formas de inscrever a escrita no filme.

No filme, isto é evidente na cena em que um ator (Osório Mateus) surge sentado na mesa de um café, fitando um livro aberto que está pousado na mesa à sua frente. No canto superior direito do ecrã aparece a inscrição "Manucure de Mário de Sá-Carneiro", e o ator dá início à leitura do referido poema. É visível uma intenção, ainda que ínfima, de encenar o texto, dado que depois de ser declamado o quarto verso - "Entanto eis-me sozinho no Café" (Sá-Carneiro 2017: 157) - surge um contra campo que mostra o café vazio e desarrumado. Entretanto, a leitura prossegue, agora em off, tendo, no entanto, sido excluída uma grande parte do poema, já que o verso que é declamado de seguida - "Ó beleza futurista das mercadorias!" (idem: 159) - é bastante posterior. A leitura continua a partir desse verso enquanto o plano abre e enquadra um empregado que arruma a confusão do café colocando as cadeiras em cima das mesas (e anunciando que está na hora do fecho). 0 empregado 
passa para a sala seguinte (onde se encontra a câmara, que recua para o acompanhar) e surge outro empregado fazendo o mesmo trabalho nesta segunda sala, enquanto a leitura do poema - única banda sonora de toda a cena - prossegue. Depois, a câmara regressa ao declamador, que vira uma página do livro e desenha, num pequeno monte de açúcar derramado na mesa, um traço que tem a forma de uma onda enquanto lê o verso "É no ar que ondeia tudo! É lá que tudo existe" (idem: 161).

Um primeiro aspeto a salientar, e que é constante ao longo do filme, é o privilégio dado à realização oral da escrita através de um tipo de encenação que expõe o seu carácter artificial, à semelhança do que sucede numa cena anterior que mostra Sá-Carneiro a declamar uma das suas cartas enquanto a escreve, sendo, tal como este ator, e apesar da situação "incomum" que as suas leituras representam, ignorado por quem o rodeia. Em termos puramente fílmicos, a leitura em voz alta de um texto escrito não é menos convencional do que o uso de uma voz sobreposta para revelar os pensamentos ou o conteúdo da escrita de uma personagem; em todo o caso, por ser um recurso que subverte a transparência ficcional da narrativa "clássica" do cinema, apresenta-se, aqui, não apenas enquanto forma privilegiada de relacionar o cinema com a escrita, mas, principalmente, como meio para acentuar a presença dessa mesma escrita e de expor, ao mesmo tempo, o carácter artificial do cinema que a exibe. Não é essa, porém, a particularidade mais importante da cena, mas, antes, o instante em que o ator desenha o traço no açúcar derramado na mesa, já que o mesmo mimetiza a forma tipográfica do referido verso no poema de Sá-Carneiro, sendo, portanto, a reprodução do mesmo numa outra superfície. A peculiar forma do verso é conduzida, portanto, do papel onde foi inscrito o poema para a mesa do café e, também, para o cinema que o apresenta/representa, por via de um percurso da mise en page para a mise en scène que transforma a superfície do cinema numa superfície de escrita. E deste modo, o filme cria uma relação entre oralidade, materialidade poética e imagem fílmica, potenciando a sua exploração em diferentes registos e através de suportes distintos.

A referida exploração pode ainda ser encontrada na cena em que um locutor de rádio (Joaquim Furtado) está no interior de um estúdio a ler, de uma resma de papéis que 
segura com as mãos, excertos da "Ode Marítima” de Álvaro de Campos. Também aqui, o poema é declamado não pelo ator que encarna o autor do texto, mas por uma figura da contemporaneidade que está enquadrada num cenário onde, em situação oposta à dos cenários de recorte deliberadamente artificial em que (normalmente) surgem Pessoa e SáCarneiro, avultam elementos que pertencem à chamada esfera do "real" o que abre a hipótese de encarar Conversa Acabada como um "híbrido" entre a ficção e o documentário. 5 Além disso, este outro registo fílmico vem convocar uma sintaxe cinematográfica distinta, pois enquanto os momentos protagonizados pelos dois poetas sublinham o carácter fotográfico da imagem através do predomínio do plano fixo, nestes é possível verificar uma maior abundância de movimentos de câmara, como o já referido contra campo entre a imagem do declamador e a dos empregados do café ou o travelling pelo estúdio de rádio nesta cena. Estas diferenças na representação fílmica são, contudo, inteiramente motivadas pela sua consonância com os movimentos da escrita entre suportes que as cenas apresentam, tanto da superfície das folhas de papel para o registo oral, como ainda para uma outra superfície (a mesa do café) e para um outro medium (a sua transmissão enquanto conteúdo radiofónico) ${ }^{6}$, situação que afirma Conversa Acabada como um filme inteiramente consciente das capacidades intermediais do cinema.

Este carácter consciente é também notório na forma claramente reflexiva que o filme utiliza para apresentar a escrita de Pessoa e de Sá-Carneiro. Veja-se, a este propósito, a cena que apresenta um excerto da carta de Pessoa a Adolfo Casais Monteiro sobre a génese dos heterónimos, datada de 13 de janeiro de 1935. Esta começa por mostrar a silhueta obscura de Pessoa, de chapéu, tendo atrás de si um céu noturno e estrelado, enquanto se ouve um som de vento cortante, que continua durante toda a cena. A silhueta ilumina-se e vemo-lo fitando a objetiva. Entretanto, este plano é substituído por outro, mais aberto, permitindo verificar que atrás do poeta está colocado um telão de animatógrafo a representar a Praça do Comércio, em Lisboa. À sua esquerda, encontra-se outra silhueta, mais concretamente aquela que o representa caminhando pela rua, e que se tornou icónica. Sobrevoam ligeiramente por todo o cenário, e devido à ação do vento, inúmeros papéis amarrotados. No canto superior direito do ecrã, surge a inscrição “Carta a Casais Monteiro de 1935”, ao 
mesmo tempo que ele declama: "Foi o dia triunfal da minha vida e nunca poderei ter outro assim” (Pessoa 1987: 326). Ouvem-se, depois, as sirenes dos cacilheiros no rio (que não são vistos), enquanto Pessoa continua a declamar a carta, e, no momento em que diz "sem interrupção nem emenda" (ibidem) a sirene abafa a sua voz - questão que dialoga com a tecnologia e também com a "Ode Marítima" - precisamente no momento em que menciona Álvaro de Campos. Quando finaliza a frase acende um cigarro da marca Provisórios, algo que, como os papéis ou a cidade de Lisboa, era omnipresente na sua vida.

Repete-se, pois, o recurso de realização oral do texto, mas de um modo inteiramente distinto. Se é possível reconhecer na cena a solução teatral do solilóquio, existe nela, por outro lado, uma abordagem performativa que perturba a transparência cinemática, tendo em conta o tipo de recitação adotada pelo ator, que se afasta, de forma bem vincada, da afetação reservada a este tipo de textos quando ditos em voz alta, parecendo até que "[n]ão é pedido aos atores para interpretar um texto - que seu fraseado literário faz com que seja, aliás, impossível de ser interpretado - e tampouco para vivê-lo: mas somente para dizê-lo" (Bazin 1991: 112). Além disso, ela inclui um particular efeito que é comparável ao dos filmes autorreflexivos e "distanciadores” de Robert Bresson, Danièle Huillet e Jean-Marie Straub $^{7}$ ou, e talvez de forma mais sintomática, à prática fílmica do realizador do Cinema Novo Alemão Hans-Jürgen Syberberg, como se pode verificar por esta descrição de Arlindo Machado:

Deliberadamente teatral, ou mais propriamente "operática", essa obra representa, em todos os sentidos, o golpe mais radical no coração disso que até aqui conhecíamos como a "linguagem" do cinema: seus cenários são apenas rascunhados e anti-realistas por excelência; suas cores completamente artificiais, com rupturas de tom entre o primeiro plano e o fundo; a maquiagem é carregada como no cinema mudo; a direcção de atores nada tem de naturalista e molda gestos e poses estilizados em atores-estátuas [...] uma câmera rigorosamente fixa [...] invariavelmente frontal, enquadra tudo isso em planos quase sempre abertos, enquanto os atores entram e saem do seu campo de visão segundo as marcações rigorosas da encenação. (Machado 2001: 275-276)

Tal descrição permite reconhecer Syberberg como uma evidente referência estética em Conversa Acabada, particularmente no décor antirrealista onde o ator se posiciona de 
uma forma estilizada declamando o texto através de um efeito verbal de distanciamento, no qual se investe não na reconstituição dos factos mas na subordinação ao texto, e onde "os atores apresentam as suas personagens, não como ficção, mas como intermediários entre si e o acontecimento, impedindo toda a falsa identificação entre a imagem e o espectador" (Araújo 2016: 190-191).

0 mesmo efeito é também verificável na forma como a personagem se separa do cenário e se torna numa entidade corpórea e palpável que se encontra dicotomizada da sua irrealidade, assumindo a forma de um elemento inteligível contra o ruído urbano (ou seja, o ruído do vento e dos papéis). Também na cena inaugural de Vertigo (1958), ou na primeira cena em que surge a residência da protagonista de Marnie (1964), ambos filmes de Alfred Hitchcock, o cenário de fundo é irreal e não oculta essa situação, e nos dois casos é ainda sugerido, de forma declarada, que as personagens se destacam de forma vívida em relação ao mesmo. Aquilo que diferencia, em primeira instância, estes exemplos do que sucede em Conversa Acabada é que neste os protagonistas se destacam principalmente pela forma reflexiva com que utilizam a palavra.

Tom Conley, escrevendo sobre o cinema de Manoel de Oliveira, refere que o mesmo "mostra aos seus espetadores, com os seus cenários altamente teatrais, que o poder expressivo do cinema deriva menos [...] de maneiras de falar do que simplesmente - e aqui claramente menos é mais - da escrita na sua condição de inscrição opaca" (Conley 2016: 18). Mais do que escrita, a expressão a sublinhar nesta afirmação é opaca, já que Botelho, e principalmente em momentos como o que foi apresentado, também subverte a transparência do cinema - ou seja, torna-o opaco ${ }^{8}$ - precisamente com a referida artificialidade no cenário e na performance, que acentuam e destacam o texto declamado enquanto ato de escrita. De que forma? Destituindo o funcionamento in absentia da carta, como é procedimento comum no cinema de recorte mais clássico, e optando por uma mise en scène opaca e reflexiva, que acentua antes, no filme, a sua componente textual.

Esta questão conduz a um outro exemplo: a cena em que Sá-Carneiro, estando deitado na cama com a sua amante francesa, subitamente recita a frase "Eu queria ser mulher pra me poder estender/Ao lado dos meus amigos, nas banquettes dos cafés" (Sá- 
Carneiro 2017: 173). Trata-se do primeiro verso do seu poema "Feminina". Ela olha-o espantada e pergunta, em francês: “O que dizes?" Ele, no entanto, ignora-a, e continua a recitação. A inquietação dela cresce, essencialmente por ele falar numa língua que lhe é estrangeira. Ele manda-a calar-se e ergue-se da cama, continuando: "Eu queria ser mulher para mexer nos meus seios [...]" (ibidem). Ela, por sua vez, levanta-se também e prepara-se para ir embora, mas Sá-Carneiro não deixa de recitar o poema na quase totalidade, ao mesmo tempo que a sua atitude perante ela parece oscilar entre o espanto e o asco.

A cena tem uma singularidade que deve ser notada: embora existam outros momentos em que um dos dois protagonistas declama um texto na presença de outras pessoas, este é o único em que a fronteira entre o "eu" e os outros se torna mais porosa, dado que a amante, confrontada com um exercício que nivela a opacidade e a transparência, se vê envolvida numa circunstância em que estranha o texto (tanto por via da língua estrangeira em que Sá-Carneiro se exprime como pelo próprio insólito da situação) ao mesmo tempo que o reconhece através desta confluência do território da escrita com o território mundano que não ocorre em nenhum outro lugar do filme. Mas o seu desenvolvimento esclarece o motivo para isso, já que a ideia transmitida é de que o poema está a ser composto perante o espetador, de uma forma que espelha as reações da amante. Veja-se que quando ela se levanta da cama, incomodada, Sá-Carneiro declama: "Eu queira ser mulher para que me fossem bem estes enleios/Que num homem, francamente, não se podem desculpar" (ibidem), e que ao mirar-se no espelho antes de se ir embora, perante o olhar dele, os versos declamados são "Eu queria ser mulher para excitar quem me olhasse/ Eu queria ser mulher para me poder recusar..." (ibidem).

Então, mesmo que o filme pareça convocar, outra vez, estratégias clássicas da elisão da escrita no cinema - aqui, o predomínio da voz —, a forma como apresenta a utilização da mesma permite concluir, como faz Amândio Reis (2016: 130) a propósito de Le Horla (1966), de Jean-Daniel Pollet, que esta é utilizada não para representar, mas, sim, para escrever, isto é, para inscrever uma reinterpretação de um texto num novo medium, projetando-o para o local onde se escreve. A própria forma como a cena se estrutura 
demonstra não só que esta depende claramente dessa escrita, mas, também, que se consubstancia por via do próprio ato de estar a ser escrita.

Estaremos perante formas particulares de remediação da escrita para o cinema? E se $\operatorname{sim}$,

Which is the medium that reflects, remediates the other? It is not the usual case in which literature is seen through cinema or vice versa, it is not even the case in which a newer medium remediates an older one, but quite the opposite: cinema seen through the filter of a seemingly archaic medium of moving pictures. However, this is a form that has never existed as such. (Pethő 2010: 328)

Com efeito, se a medialidade do cinema é geralmente considerada como "invisível", Conversa Acabada torna o invisível em visível através da utilização de técnicas que visam sublinhar, pela aplicação da superfície fílmica como suporte de inscrição, a materialidade do cinema dos primórdios, ou seja, o tipo de medialidade que tem as suas raízes na representação e na indexicalidade fotográfica, com as suas conexões infinitas com as artes e com a cultura, e que veio progressivamente a desaparecer com os avanços da tecnologia que promovem a transparência do dispositivo. Desta forma, o filme apresenta algo de familiar: por um lado, o fascínio com o índice fotográfico, e por outro, a materialidade tangível da arte. E fá-lo através de técnicas que podem, em grande medida, ser encaradas como primitivas ou arcaicas, dando origem a um tipo de cinema "artesanal" que comunica primariamente um senso de textura que enfatiza a implicação corporal na criação artística, ou antes, os traços e as impressões da performatividade da criação: o ato de escrita nas suas várias formas, o manusear de um livro, as vozes comunicantes, e os próprios gestos dos atores. Todo o filme se baseia nestas realidades palpáveis.

Será então possível, como refere André Bazin ao dissertar sobre a adaptação do romance Journal d'un Curé de Campagne, de Georges Bernanos, por Robert Bresson, colocar a hipótese de ser também este "um filme mudo com legendas faladas?" (Bazin 1991: 116). $\mathrm{Na}$ verdade, não o é propriamente, porque a forma como Botelho estabelece as relações entre a imagem e a palavra revelam a heterogeneidade dos media, o que permite concluir, tal como o próprio Bazin sobre o seu objeto de estudo, que “a sua estilização não é a 
abstração a priori do símbolo, ela constrói-se numa dialética do concreto e do abstrato pela ação recíproca de elementos contraditórios da imagem" e que esta dialética "arranha a imagem para denunciar a transparência como uma poeira de diamante. É a impureza em estado puro" (idem: 110).

Conversa Acabada é um produto híbrido onde a letra, a imagem, a escrita e a leitura, que pertencem tanto à História da cultura como à da representação visual, exigem um abrandamento na ação narrativa e um tipo específico de olhar, de ouvir e também de ler por parte do espetador. Esta questão recorda aquilo que Ágnes Pethő denomina de "porosidade bidirecional da imagem em movimento" (2010: 96), tanto para o que percebemos como "realidade" como para a própria medialidade refletida na intermedialização da imagem. Esta, filtrada através das outras artes ou reformulada por outros meios, transforma-se, assim, em qualquer coisa de intermédio.

\section{NOTAS}

1 "Primeiro Fausto", Páginas Íntimas e de Auto-Interpretação, "Epithalamium", "Hora Absurda", "Chuva Oblíqua", "Além-Deus", “Carta a Adolfo Casais Monteiro de 13 de Janeiro de 1935", “Antinous”, “Crónica da vida que passa", "O Marinheiro" e "Nevoeiro" (de Mensagem), de Fernando Pessoa; "Eu nunca guardei rebanhos...", “Ao entardecer, debruçado pela janela...”, "Há metafísica bastante em não pensar em nada...”, “O meu olhar azul como o céu..." e "A espantosa realidade das cousas...", de Alberto Caeiro; "Vem sentar-te comigo, Lídia, à beira do rio..." e "Melhor destino que o conhecer-se...", de Ricardo Reis; "Soneto já antigo", “Ode Triunfal”, “Ode marítima” e "Passagem das horas", de Álvaro de Campos. 
2 "Dispersão", "Inter-sonho", "Álcool”, A Confissão de Lúcio, "Manucure”, "Crise lamentável”, "Aqueloutro", "Feminina", "Sete canções do declínio".

${ }^{3}$ Interpretadas, respetivamente, por Fernando Cabral Martins e André Gomes.

${ }^{4}$ Veja-se, por exemplo, Dangerous Liaisons (Stephen Frears, 1988), uma das adaptações cinematográficas do romance epistolar Les Liaisons Dangereuses, de Choderlos de Laclos. Ainda que este filme invista na correspondência epistolar do livro, a mesma é naturalizada na diegese fílmica e serve apenas como base para os elementos da intriga. De facto, o momento de escrita das cartas é raramente encenado no filme, privilegiando-se antes o momento da sua receção, de modo que aquilo que erige o livro (os vários registos escritos que constituem o seu relato) fique relegado para um registo do idealizado ou mesmo do omisso, e seja criado um efeito de transparência narrativa.

${ }^{5}$ De facto, o filme foi inicialmente projetado para ser um documentário, situação patente não apenas nestas cenas, em que diferentes pessoas declamam textos de Fernando Pessoa e de Mário de Sá-Carneiro, mas também na presença da voz over de uma narradora e na de um "apresentador" de dados biográficos dos dois poetas e eventual declamador de textos (Jorge Silva Melo). Apesar de o filme ter evoluído para se tornar num retrato da conversa essencialmente epistolar dos dois poetas, João Botelho optou por manter as cenas mais "documentais" na montagem final.

${ }^{6}$ A questão radiofónica remete ainda para o poema de Mário de Sá-Carneiro "A minh'alma fugiu pela Torre Eiffel acima", que apresenta os versos "Fugiu, mas foi apanhada pela antena da T.S.F./Que a transmitiu pelo infinito em ondas hertzianas..." (idem: 171).

${ }^{7}$ Vejam-se as várias intervenções das diferentes personagens de Sicilia! (1999).

${ }^{8} 0$ termo é aqui entendido de acordo com a dicotomia, estabelecida por Ismail Xavier, entre a cinematografia que visa um regime de transparência, ou seja, um "efeito-janela, quando se favorece a relação intensa do espectador com o mundo visado pela câmara" (Xavier 2005: 9), e a que procura um regime de opacidade, que neste caso se baseia em "operações que reforçam a consciência da imagem como um efeito de superfície" e que "tornam a tela opaca e chamam a atenção para o aparato técnico e textual que viabiliza a representação" (ibidem). 


\section{Bibliografia e filmografia}

Alpers, Svetlana (1987), El Arte de Describir. El Arte Holandés en el Siglo XVII, Madrid, Hermann Blume.

Araújo, Nelson (2016), Cinema Português. Interseções Estéticas nas Décadas de 60 a 80 do Século XX, Lisboa, Edições 70.

Bazin, André (1991), “O Journal d'un Curé de Campagne e a estilística de Robert Bresson”, in o Cinema. Ensaios, tradução de Eloísa de Araújo Ribeiro, São Paulo, Editora Brasilense. 105122.

Botelho, João (1981), Conversa Acabada, 100 minutos, Sonoro, Cor, Português.

Conley, Tom (2016), "Falso movimento: Reflexões sobre escrita e cinema" (tradução de Clara Rowland), in Falso Movimento. Ensaios sobre escrita e cinema, Ed. Clara Rowland e Tom Conley, Lisboa, Cotovia. 15-21.

Guido, Laurent (2012), “The Supremacy of the Mathematical Poem': Jean Epstein's Conceptions of Rhythm", in Jean Epstein. Critical Essays and New Translations, Ed. Sarah Keller e Jason N. Paul, Amsterdam, Amsterdam University Press. 143-160.

Machado, Arlindo (2001), Máquina e Imaginário. O desafio das poéticas tecnológicas, São Paulo, EDUSP.

Pessoa, Fernando (1987), “Carta a Adolfo Casais Monteiro de 13 de janeiro de 1935”, in Obras em Prosa, Volume V, Lisboa, Círculo de Leitores, 323-329.

Pethő, Ágnes (2010), Cinema and Intermediality, Newcastle upon Tyne, Cambridge Scholars. Reis, Amândio (2016), "Como um seixo na praia": Outra forma de escrever (0 Horla)", in Falso Movimento. Ensaios sobre escrita e cinema, Ed. Clara Rowland e Tom Conley, Lisboa, Cotovia, 126-144. 
Sá-Carneiro, Mário de (2017), Poesia Completa de Mário de Sá-Carneiro, Vasconcelos, Ricardo (ed.), Lisboa, Tinta-da-china.

Veiga, B. (2010), "A imagem na obra de João Botelho", <http://b-veigareflexoes.blogspot.pt/2010/10/introducao-o-trabalho-sob-o-qual-me.html> (último acesso em 10/06/2019).

Xavier, Ismail (2005), O Discurso Cinematográfico. A opacidade e a transparência, São Paulo, Editora Paz e Terra.

Bruno Fontes licenciou-se em Estudos Portugueses e Lusófonos na Faculdade de Letras da Universidade de Coimbra e concluiu o Mestrado em Estudos Artísticos, na área de Estudos Fílmicos, na mesma instituição. Está neste momento a frequentar o Doutoramento em Materialidades da Literatura na Universidade de Coimbra, no âmbito do qual desenvolve uma tese acerca da representação da escrita na imagem fílmica nos casos em que o dispositivo é utilizado de forma reflexiva, com a orientação científica do Professor Doutor Osvaldo Manuel Silvestre (orientador) e do Professor Doutor Ricardo Namora (coorientador). 